\title{
Phylogenetic community structure reveals differences in plant community assembly of an oligotrophic white-sand ecosystem from the Brazilian Atlantic Forest
}

\author{
Markus Gastauer ${ }^{1,2}$, Amílcar W. Saporetti-Junior ${ }^{1,3}$, Fernando Valladares ${ }^{4}$ and João A. A. Meira-Neto*
}

Received: December 12, 2016

Accepted: March 3, 2017

\begin{abstract}
Mussununga, an oligotrophic sandy savanna ecosystem, comprises distinct physiognomies along fire, water and nutrient availability gradients. Grasslands and woodlands are constrained at the opposite poles of these gradients, with grasslands occurring in areas with poorer soils and higher levels of both water-stress and fire intensity. According to the stress-dominance hypothesis, one might expect the importance of competition for community assembly to increase from grasslands to woodlands. Assuming conservation of ecological niches within evolutionary lineages, this should increase phylogenetic overdispersion from grasslands towards woodlands. To test this, we calculated phylogenetic diversity and community structure using different null models as well as the phylogenetic signal of life form as a proxy of niche space. All indices indicate phylogenetic clustering for grasslands and phylogenetic overdispersion for woodlands. Considering that most life-forms showed a significant phylogenetic signal, findings indicate that competition and further density dependent factors may play a larger role in community assembly of physiognomies in less harsh positions along the gradient, while environmental filtering dominates the harsher positions. Our results indicate that the entire gradient should receive conservation priority in order to guarantee the effective conservation of this endangered ecosystem, including its species richness and ecological processes such as community assembly.
\end{abstract}

Keywords: competition, environmental filters, Mussunungas, savanna woodlands, stress-dominance hypothesis

\section{Introduction}

Environmental filters, also known as abiotic constraints (Kraft et al. 2015), restrict the presence of organisms within a community to individuals possessing certain morphological, physiological or phenological trait values (Rickleffs 2007; Leibold et al. 2010), while competitive exclusion occurs as a result of ecological niche overlap (Elton 1927; Hutchinson 1957). Convergent or random trait evolution can influence phylogenetic community composition in manifold ways (Cavender-Bares et al. 2009), but if niches are conserved within evolutionary lineages (e.g., Davies et al. 2004; Díaz et al. 2004; Baraloto et al. 2012), so that close relatives share more functional traits and show higher niche overlap, the dominance of environmental filters in community assembly will result in phylogenetic clustering (MacArthur \& Levins 1967; Weiher \& Keddy 1995; Baraloto et al. 2012). On the other hand, the dominance of negative interactions, such as competition and other density-dependent factors, can result

\footnotetext{
${ }^{1}$ Laboratório de Ecologia e Evolução de Plantas, Departamento de Biologia Vegetal, Universidade Federal de Viçosa, Av. Peter Henry Rolfs s/n, 36570-900, Viçosa, MG, Brazil

${ }^{2}$ Instituto Tecnológico Vale, Rua Boaventura da Silva, 955, 66055-093, Belém, PA, Brazil

${ }^{3}$ Laboratório de Ecologia de Restinga e Mata Atlântica, Centro Universitário Norte do Espírito Santo/Universidade Federal do Espírito Santo, 29932-900, São Mateus, ES, Brazil

${ }^{4}$ Consejo Superior de Investigaciones Cientificas - CSIC, Calle Serrano 115, 28006, Madrid, Spain

* Corresponding author: j.meira@ufv.br
} 
in phylogenetic overdispersion due to the exclusion of close relatives (Helmus 2007; Cahill Jr. et al. 2008). Alternatively, stochastic community assembly (i.e., Hubbell 2001) should result in phylogenetic community structure that does not differ from the null expectation (Webb et al. 2002; Kembel \& Hubbell 2006; Hardy 2008). As negative interactions are expected to be more important in less harsh habitats, the stress-dominance hypothesis postulates phylogenetic overdispersion in such environments, while phylogenetic clustering is expected in harsher habitats (Swenson \& Enquist 2009). Therefore, phylogenetic approaches show promise in enabling ecologists to understand the assembly, functioning and maintenance of different physiognomies and their biodiversity (Belwood et al. 2002; McGill et al. 2006; Bello et al. 2012; Carvalho \& Batalha 2013), especially when measurements of functional traits are not available (Flynn et al. 2011; Faith 2015).

The occurrence of different physiognomies and patterns of species richness in Mussununga vegetation is correlated with soil properties and landscape relief (Saporetti-Junior et al. 2012). Mussununga means "soft and wet white sand" in the Amerindian Tupi-Guarani language (Meira-Neto et al. 2005), and thus Mussununga vegetation refers to an oligotrophic savanna-type of formation endemic to the Brazilian Atlantic Forest in southern Bahia and northern Espírito Santo states where it occurs on shallow sandy Spodsol patches (IBGE 2004; Araujo et al. 2008; Simonelli et al. 2008). Mussununga vegetation comprises different physiognomies, ranging from more or less open formations (i.e., grasslands) to woodlands. Both Mussununga grasslands and shrublands are mostly covered by an herbaceous stratum, although shrublands also comprise scattered shrubs. Mussununga woodlands, on the other hand, are covered by a dense tree stratum with a sparsely-distributed herbaceous layer (Batalha et al. 2001). These physiognomies occupy restricted ranges on abiotic gradients of water availability, nutrient supply and intensity of fire (Saporetti-Junior et al. 2012). Mussununga grasslands are established on the harsher end of the gradient characterized by low nutrient and low water retention due to a higher percentage of coarse sand and reduced soil depths (until the Ortstein stratum) as well as frequent and intense inundations during the rainy season. Mussununga woodlands, in contrast, are found on less harsh portions of the gradient with a higher percentage of fine sand and a deeper Ortstein stratum, while typical savanna vegetation is found intermediately along the gradient. Among Mussununga physiognomies, fire intensity increases from woodlands to grasslands, while species richness increases from grasslands to woodlands.

The objective of this work is to analyze phylogenetic diversity and community structure of Mussununga vegetation across different physiognomies in order to gain insights into Mussununga community assembly. Therefore, we aimed to test: (i) if phylogenetic community structure fulfills the expectations of the stress-dominance hypothesis, that is, exhibit phylogenetic clustering in harsher habitats (grasslands) and phylogenetic overdispersion in less harsh habitats (woodlands); and (ii) if life form, a proxy of niche space, shows phylogenetic signal indicating its conservation within evolutionary lineages. For the latter we tested whether the net relatedness index (NRI) for each life form is significantly greater than zero.

\section{Materials and methods}

\author{
Study site
}

Field surveys were carried out in a Mussununga patch $\left(17^{\circ} 41^{\prime} \mathrm{S}, 39^{\circ} 29^{\prime} \mathrm{W}\right)$ in the municipality of Caravelas, in southern Bahia State, Brazil (Saporetti-Junior et al. 2012). With a total size of 850 ha, this patch is one of the largest and best-preserved Mussunungas in the region, and possesses a small-scaled mosaic of all three different Mussununga physiognomies: grassland, shrubland and woodland.

According to the Köppen classification, the climate of the region is Af, which is a humid tropical climate type with mean annual precipitation of approximately $1,750 \mathrm{~mm}$ (Köppen 1923). Rainy summers alternate with moderately dry winters in the region.

The region has a flat relief above Tertiary sandstones of the Barreiras Group. The dominant vegetation of the landscape is evergreen tableland forest belonging to the Atlantic Forest domain. The predominant soil type in the region is Podsols, upon which the tableland forests stand. Mussununga vegetation is restricted to sandy Spodosol insertions within the Podsol matrix, where the high sand content reduces nutrient and water availability (SaporettiJunior et al. 2012).

\section{Data collection}

For delimitation of the Mussununga species pool, samples of all angiosperms from the entire Mussununga patch were collected, identified and deposited in the VIC herbarium of the Federal University of Viçosa, Brazil. The species list for this study was compiled from records published by MeiraNeto et al. (2005). All species were classified according to APG IV (2016).

In each of the three different Mussununga physiognomies (grassland, shrubland and woodland) two plots of $20 \mathrm{x}$ $20 \mathrm{~m}$, subdivided in 40 subplots of $2 \times 5 \mathrm{~m}$, were installed. Abundance data, (i.e., number of individuals) for each species were collected as individual counts in each subplot. Furthermore, species were classified in the field according to their life forms as phanerophytes, chamaephytes, hemicryptophytes, geophytes, terophytes or lianas, following Raunkiaer (1934). 


\section{Phylogenetic community structure reveals differences in plant community assembly of an oligotrophic white-sand ecosystem from the Brazilian Atlantic Forest}

\section{Phylogenetic diversity and community structure}

We computed the mean pairwise distance (MPD), the mean nearest taxon distance (MNTD, Webb et al. 2002) and phylogenetic diversity (PD, Faith 1992) for each subplot using the 'picante' package in $\mathrm{R}$ version 3.2.4 (R Core Team 2016). Because these raw phylogenetic diversity measures are correlated with taxonomic diversity (Webb 2000; Kembel et al. 2010), we furthermore computed the standard effect sizes (SES) of these measurements.

To construct the phylogeny for Mussununga vegetaion, we used the new angiosperm family tree R20160415. new (Gastauer \& Meira-Neto 2017), which represents phylogenetic relationships among angiosperms as recently proposed by APG IV (2016), thus guaranteeing the inclusion of the most up-to-date information about angioserm phylogenetic relationships in our analysis. All species from the Mussununga species pool were inserted in the family tree using the phylomatic function of the Phylocom 4.2 package (Webb \& Donoghue 2005). The resulting community tree was dated using the bladj algorithm with mean age estimates from Bell et al. (2010).

Indices of phylogenetic community structure (ses.mpd, ses.mntd and ses.pd) were calculated using phylogeny pool and independent swap null models. The phylogeny pool null model maintains the number (and abundance) of species from each plot as a constant, but randomly shuffles the identities of the species occurring in each plot; the inter-site abundance distribution of each species is not maintained (Hardy 2008). The independent swap null model shuffles species occurrences (and abundances) among all plots in a way that species richness, as well as species frequency/ abundance among all plots, is maintained constant. This model assumes that the ability of a species to colonize a plot is proportional to its frequency in the survey, while each species has an equal probability of occurring within each plot by the unconstrained null model. Since the intersite species abundance distribution is maintained by the independent swap (Gotelli \& Graves 1996; Gotelli 2000; Gotelli \& Entsminger 2001), this null model breaks down any spatial autocorrelation of local species occurrence or abundance (Hardy 2008).

To test for statistical significance in phylogenetic structure, a one-sample t test against zero was conducted for the indices from all subplots from a physiognomy after testing for a normal error distribution. Significant differences among the physiognomies were inferred by mixed models using 'lme' from the 'lmer' package, and considering plots as random effects (R Core Team 2016).

\section{Phylogenetic signal of life form}

To test if the functional trait of life form possessed phylogenetic signal (i.e., the tendency of related species to resemble each other more than species drawn at random from the same tree), we computed the NRI among all species from the same life form, hereafter called LifeFormNRI. This was accomplished by shuffling taxon labels 10,000 times across the phylogeny.

Values of LifeFormNRI significantly higher than zero indicate phylogenetic signal. Conservation of life form was considered significant when the observed MPD occurred in the lowest $2.5 \%, 1 \%$ or $0.1 \%$ of the distribution of distances from the null models, corresponding to the significance levels of $0.05,0.01$ or 0.001 , respectively.

\section{Phylogenetic resolution}

The presence of more than two species in the species pool from a single genus, as well as the occurrence of more than two genera from a single family, produces polytomies when building the Mussununga vegetation phylogeny by the phylomatic function. The number of polytomies in the phylogeny is a measure of lack of phylogenetic resolution. To outline the influence of the lack of phylogenetic resolution on the outcome of phylogenetic community structure analysis and its interpretation, we randomized all polytomies present in the community phylogeny 999 times using the 'multi2di' function from the 'picante' package ( $R$ Core Team 2016). We dated each randomization using the bladj algorithm. We then calculated NRI and NTI for each subplot from each of the 999 fully resolved phylogenies as described above and compared outcomes from randomly resolved with unresolved phylogenies.

\section{Results}

One hundred and twenty-three species of angiosperms were found in the 0.24 ha survey area. Together with the taxa found by Meira-Neto et al. (2005; 66 angiosperm species), our Mussununga angiosperm species pool comprises 188 species (Fig. 1). Four out of six life-forms possessed a LifeFormNRI higher than expected by chance (Tab. 1).

MPD and PD were lowest for grasslands (Fig. 2), and shrublands had lower PD than woodlands. MNTD was highest for shrublands, and did not differ between grasslands and woodlands. ses.mpd, ses.mntd and ses.pd indicate significant phylogenetic clustering for grasslands, while woodlands exhibited phylogenetic overdispersion (Fig. 3, Tab. 2). Phylogenetic structure of shrublands was found less overdispersed than woodlands or no pattern at all, with ses.mpd, ses.mntd and ses.pd values being intermediate between those of grasslands and woodlands.

Correlations between all MPD, MNTD, PD, ses.mpd, ses.mntd and ses.pd values computed from the unresolved phylogeny and 999 randomly resolved versions showed coefficients ranging from 0.936 to 0.988 . The patterns of the values for phylogenetic diversity and community structure revealed in this study were recognized in all randomizations. 


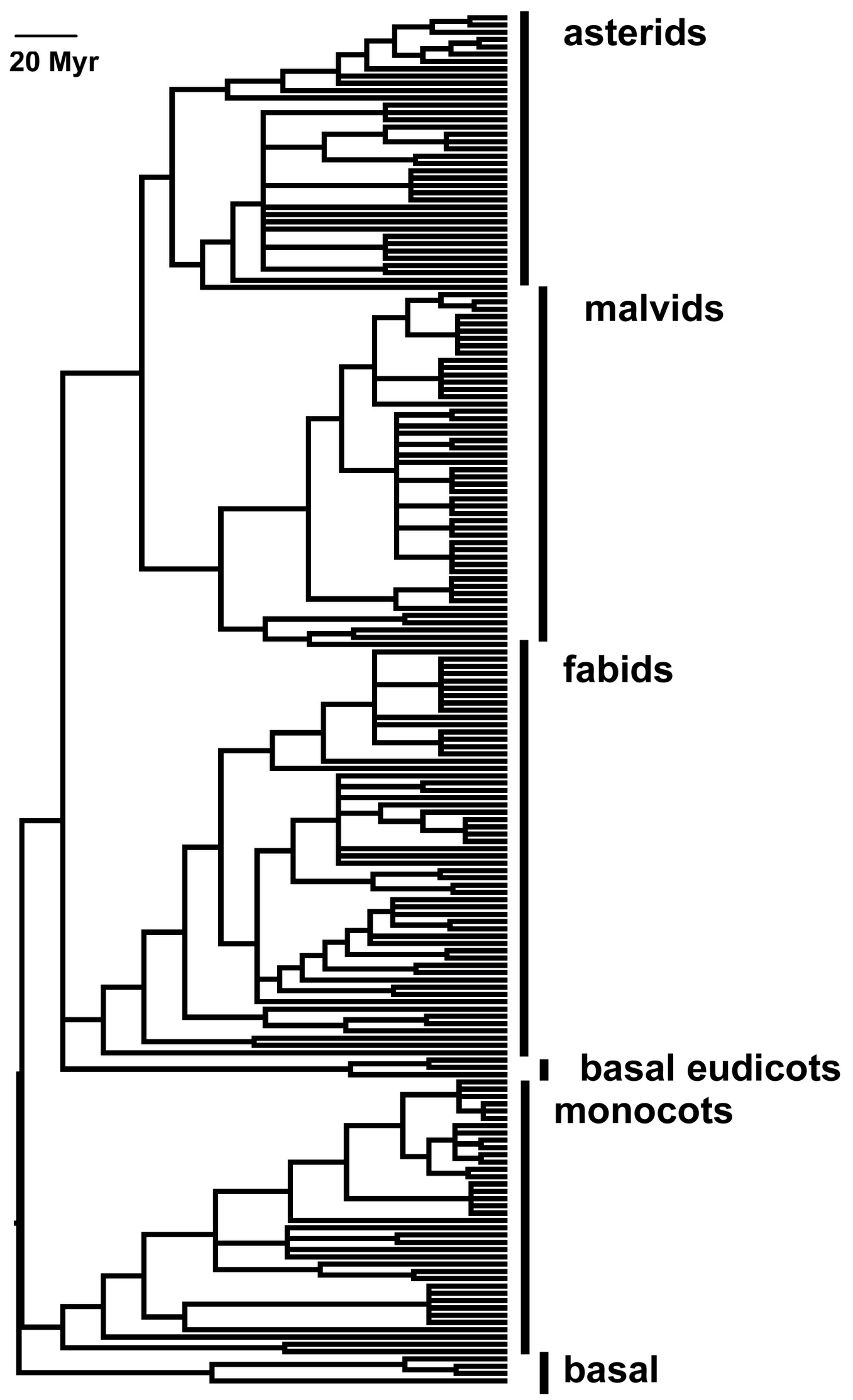

Figure 1. Phylogeny of the Mussununga angiosperm species pool. 


\section{Phylogenetic community structure reveals differences in plant community assembly of an oligotrophic white-sand ecosystem from the Brazilian Atlantic Forest}

Table 1. Distribution of life forms within the Mussununga phylogeny. Bold values of LifeFormNRI indicate that a trait life form is clustered within the phylogeny (i.e., the universe of species with the same life form are phylogenetically more related than expected by chance). $\mathrm{N}$ is the number of species with a specific life-form. P indicates the probability of LifeFormNRI being larger than zero, compared to 10,000 randomizations. See Methods for details.

\begin{tabular}{|c|c|c|c|}
\hline Life Form & N & LifeformNRI & P \\
\hline Phanerophytes & 35 & $\mathbf{3 . 3 4 1}$ & $<\mathbf{0 . 0 0 1}$ \\
\hline Chamaephytes & 57 & $\mathbf{8 . 9 4 4}$ & $<\mathbf{0 . 0 0 1}$ \\
\hline Hemicryptophytes & 24 & $\mathbf{5 . 7 5 6}$ & $<\mathbf{0 . 0 0 1}$ \\
\hline Lianas & 14 & 0.513 & 0.421 \\
\hline Therophytes & 7 & $\mathbf{8 . 0 9 5}$ & $<\mathbf{0 . 0 0 1}$ \\
\hline Geophytes & 2 & 0.261 & 0.297 \\
\hline
\end{tabular}
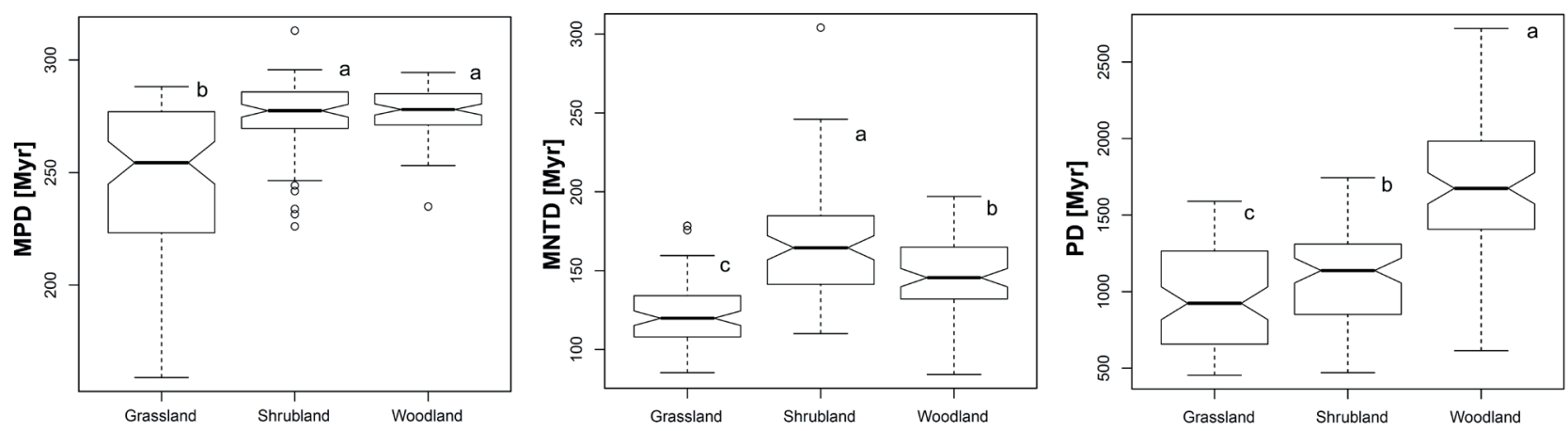

Figure 2. Mean pairwise distance (MPD), mean nearest neighbor distance (MNTD) and phylogenetic diversity (PD) for the three Mussununga physiognomies. Different letters indicate significant differences between physiognomies $(\mathrm{p}<0.05)$.
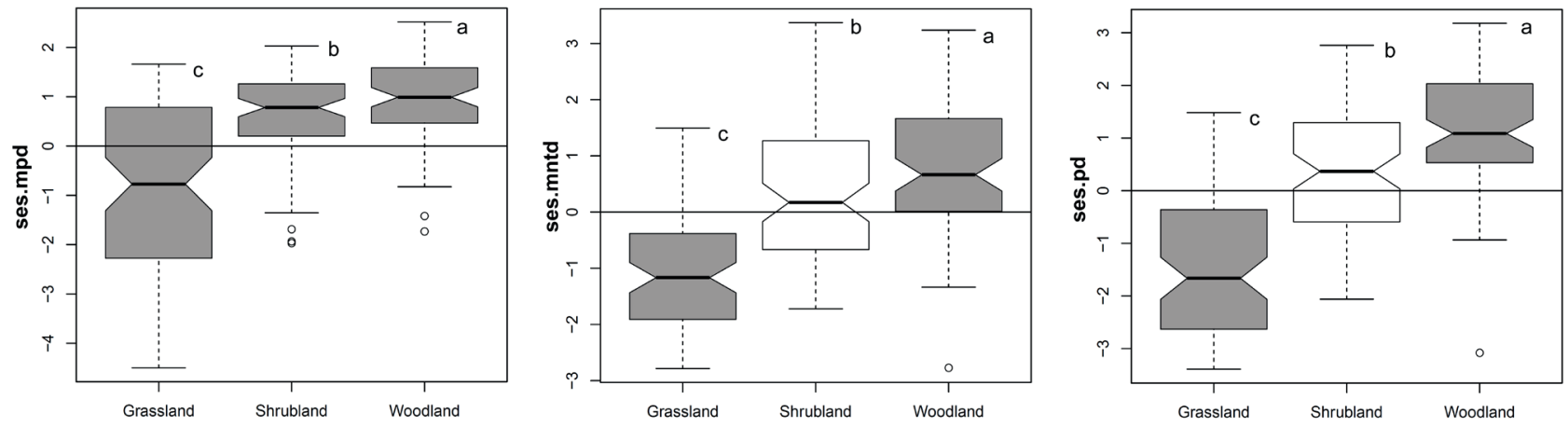

Figure 3. Phylogenetic community structure computed by the unconstrained null model for the three Mussununga physiognomies: ses.mpd, standard effect size of mean pairwise distance among distinct taxa; ses.mntd, standard effective size of mean nearest taxon distance among distinct taxa; and ses.pd, standard effective size of phylogenetic diversity. Different letters indicate significant differences between physiognomies $(p<0.05)$. Shaded bars indicate phylogenetic structure different from the null expectation $(p<0.05)$.

\section{Discussion}

Phylogenetic diversity (PD, MPD) increases from Mussununga grasslands to woodlands as does species richness (Saporetti-Junior et al. 2012). MNTD indicates lower phylogenetic diversity for woodlands than for shrublands, because the elevated species richness of the latter physiognomy tends to reduce MNTD values. Increasing indices of phylogenetic community structure (ses.mpd, ses.mntd, ses.pd) from grasslands to woodlands fulfill the expectations of the stress-dominance hypothesis, thus confirming the findings of similar previous studies (i.e., Gastauer \& Meira-Neto 2014; Miazaki et al. 2015). Positive LifeFormNRI values show that there is a tendency of related species to resemble each other more than species drawn at random from the phylogeny, indicating that close relatives share more functional traits and show higher niche overlap than expected by chance. Similar patterns from other savannalike formations have been detected by previous studies (i.e., Qian \& Zhang 2014; Moro et al. 2015; Kuhlmann \& Ribeiro 2016). 
Table 2. Phylogenetic community structure of the three Mussununga physiognomies according to different null models. Given are mean values \pm standard deviations as well as number of significantly overdispersed or clustered subplots. Different letters indicate significant differences among physiognomies. Binominal P is the probability that the number of clustered or overdispersed subplots is higher than expected by null assumption. ses.mpd is standard effective size of mean pairwise distance, and ses.mntd is standard effective size of mean nearest neighbor distance. Both indices were computed among distinct taxa as well as among individuals (abundance weighted).

\begin{tabular}{|c|c|c|c|c|c|c|}
\hline \multirow{2}{*}{ Variable } & \multirow{2}{*}{ Physiognomy } & \multirow{2}{*}{ Mean value \pm SD } & \multicolumn{2}{|c|}{ Overdispersed plots } & \multicolumn{2}{|c|}{ Clustered plots } \\
\hline & & & $\mathbf{N}$ & Binominal P & $\mathbf{N}$ & Binominal $\mathbf{P}$ \\
\hline \multicolumn{7}{|c|}{ Phylogeny pool null model } \\
\hline \multirow{3}{*}{ ses.mpd } & Grassland & $0.762 \pm 1.669 \mathrm{a}$ & 0 & 0.132 & 23 & $<0.001$ \\
\hline & Savanna & $-0.631 \pm 0.862 b$ & 1 & 0.274 & 1 & 0.274 \\
\hline & Woodland & $-0.944 \pm 0.846 c$ & 9 & $<0.001$ & 0 & 0.132 \\
\hline \multirow{3}{*}{ ses.mntd } & Grassland & $1.111 \pm 1.059 \mathrm{a}$ & 0 & 0.132 & 13 & $<0.001$ \\
\hline & Savanna & $-0.371 \pm 1.306 b$ & 12 & $<0.001$ & 0 & 0.132 \\
\hline & Woodland & $-0.792 \pm 1.116 c$ & 13 & $<0.001$ & 1 & 0.274 \\
\hline \multirow{3}{*}{$\begin{array}{l}\text { ses.mpd } \\
\text { (abundance } \\
\text { weighted) }\end{array}$} & Grassland & $1.828 \pm 1.894 \mathrm{a}$ & 0 & 0.132 & 39 & $<0.001$ \\
\hline & Savanna & $0.049 \pm 1.108 b$ & 1 & 0.274 & 7 & 0.003 \\
\hline & Woodland & $-0.687 \pm 0.978 c$ & 3 & 0.182 & 1 & 0.274 \\
\hline \multirow{3}{*}{$\begin{array}{l}\text { ses.mntd } \\
\text { (abundance } \\
\text { weighted) }\end{array}$} & Grassland & $1.585 \pm 0.922 \mathrm{a}$ & 0 & 0.132 & 31 & $<0.001$ \\
\hline & Savanna & $0.132 \pm 1.318 \mathrm{~b}$ & 5 & 0.035 & 8 & $<0.001$ \\
\hline & Woodland & $-0.227 \pm 1.17 c$ & 6 & 0.011 & 2 & 0.271 \\
\hline \multicolumn{7}{|c|}{ Independent swap null model } \\
\hline \multirow{3}{*}{ ses.mpd } & Grassland & $1.612 \pm 1.908 \mathrm{a}$ & 0 & 0.132 & 39 & $<0.001$ \\
\hline & Savanna & $-0.117 \pm 1.057 \mathrm{~b}$ & 0 & 0.132 & 5 & 0.035 \\
\hline & Woodland & $-0.217 \pm 1.245 c$ & 4 & 0.090 & 5 & 0.035 \\
\hline \multirow{3}{*}{ ses.mntd } & Grassland & $1.221 \pm 0.991 \mathrm{a}$ & 0 & 0.132 & 17 & $<0.001$ \\
\hline & Savanna & $-0.226 \pm 1.294 b$ & 10 & $<0.001$ & 0 & 0.132 \\
\hline & Woodland & $-0.619 \pm 1.189 c$ & 12 & $<0.001$ & 1 & 0.274 \\
\hline \multirow{3}{*}{$\begin{array}{l}\text { ses.mpd } \\
\text { (abundance } \\
\text { weighted) }\end{array}$} & Grassland & $0.512 \pm 1.203 \mathrm{a}$ & 0 & 0.132 & 9 & $<0.001$ \\
\hline & Savanna & $0.335 \pm 0.993 \mathrm{~b}$ & 0 & 0.132 & 7 & 0.003 \\
\hline & Woodland & $-0.716 \pm 0.955 c$ & 2 & 0.271 & 2 & 0.271 \\
\hline \multirow{3}{*}{$\begin{array}{l}\text { ses.mntd } \\
\text { (abundance } \\
\text { weighted) }\end{array}$} & Grassland & $0.868 \pm 0.788 a$ & 0 & 0.132 & 2 & 0.271 \\
\hline & Savanna & $-0.275 \pm 1.32 \mathrm{~b}$ & 0 & 0.132 & 1 & 0.274 \\
\hline & Woodland & $-0.767 \pm 1.181 c$ & 11 & $<0.001$ & 2 & 0.271 \\
\hline
\end{tabular}

Phylogenetic clustering in harsher habitats, such as the grassland physiognomy, indicate the coexistence of close relatives in more severe environments, while phylogenetic overdispersion in Mussununga woodlands shows that evolutionary less related species share the same habitat. Thus, grasslands comprise less species than the other physiognomies (Saporetti-Junior et al. 2012), and these species seem to be clustered among a few lineages.

Positive LifeFormNRIs, as was detected for most life forms of the present study, do not confirm ecological niche conservatism within evolutionary lineages (Losos 2008). Due to the categorical nature of the life form traits employed, further, more advanced metrics (e.g., Bloomberget al. 2003; Harmon et al. 2008; Hadfield \& Nakagawa 2010) could not be applied to provide deeper insights. Nevertheless, positive LifeFormNRI values provide evidence that closely related species share niche space to a higher degree than expected by chance, thus supporting the interpretation that phylogenetic overdispersion found in woodlands might be due to a higher degree of interaction, while clustering in grasslands might be caused by the dominance of environmental filters in community assembly.
Therefore, our results are consistent with a scenario where competition and other density dependent factors play a larger role in community assembly in physiognomies in less harsh locations of the environmental gradient in Mussununga vegetation (woodlands), while environmental filtering seems to dominate the harsher locations (i.e., grasslands), thus confirming the predictions of the stress-dominance hypothesis. Environmental filtering in Mussununga grasslands may be caused by restricted nutrient availability, alternating drought and flooding events or even higher fire frequency (Saporetti-Junior et al. 2012).

Nevertheless, further explanations are possible (Cavender-Bares et al. 2009). Competition might cause phylogenetic clustering (or reduce phylogenetic overdispersion) if competitive abilities are conserved within evolutionary lineages and niche differences are unimportant or unrelated to phylogeny (Mayfield \& Levine 2010). In this case, closely related superior competitors from Mussununga grasslands may outcompete distantly related species lacking competitive abilities, but it is unclear how evolutionary conserved competitive abilities could create a pattern of 


\section{Phylogenetic community structure reveals differences in plant community assembly of an oligotrophic white-sand ecosystem from the Brazilian Atlantic Forest}

phylogenetic overdispersion in savanna and woodland physiognomies (Godoy et al. 2014).

Besides pollinator-plant interactions (Sargent \& Ackerley 2008) and temporal niche dynamics (Kelly et al. 2008), facilitation is also able to create a pattern of phylogenetic overdispersion within communities (Valiente-Banuet \& Verdú 2007). Facilitation is a positive interaction promoting the coexistence of dissimilar species to avoid niche overlap (Castillo et al. 2010). As life forms, a proxy for niche space, show phylogenetic signal, the coexistence of dissimilar species should result in phylogenetic overdispersion (Soliveres et al. 2012; Valiente-Banuet \& Verdú 2013). Therefore, either a higher degree of positive (facilitation) or negative (i.e., competition density dependent factors) interactions may explain the phylogenetic overdispersion observed, although facilitation is expected to play a more important role in harsher habitats.

Although our data met the predictions of the stressdominance hypothesis, our study was carried out on a very local scale. True replicates are still lacking, which hampers extrapolation. Phylogenetic signal was computed for one trait only, and additional niche or competitive traits may show a different pattern, which might put into question the present interpretation of phylogenetic community structure measures. Furthermore, the species pool may be larger than assumed in this study, and may include species from surrounding ecosystems such as tableland forests. A larger species pool may alter computed indices of phylogenetic community structure for Mussununga physiognomies, which may influence the interpretation of results and, consequently, the conclusions.

In contrast, our findings gain confidence from the fact that the influence of lacking or limited phylogenetic resolution on our interpretations and conclusions is considerably low. Furthermore, different null models recognized all patterns of phylogenetic community structure independently, and the tendencies are consistently revealed when indices are calculated among different taxa or different individuals. However, conclusions should be verified by more comprehensive studies, including the examination of additional functional traits, to confirm the stress-dominance hypothesis and to gain further valuable insight in the assembly of Mussununga vegetation as well as in other open formations such as the Brazilian Cerrado, Campina/ Campinarana vegetation or the Llanos of Venezuela and Colombia.

Although many doubts remain, phylogenetic overdispersion increases together with species richness from grasslands to woodlands in Mussununga vegetation. As suggested by Cadotte et al. (2012), higher phylogenetic diversity in woodlands indicates higher ecosystem stability for this physiognomy. In contrast, because data indicate that differences in the underlying processes of community assembly occur along the environmental gradient, conservation priority should focus on the entire gradient. To guarantee an effective conservation of this endangered ecosystem, its diversity and its diversified underlying ecological processes such as community assembly, all physiognomies should be protected and the most heterogeneous Mussununga patches should be selected for the formation of conservation units.

\section{Acknowledgements}

The authors thank the Secretaria de Ciências, Tecnologia e Ensino Superior (SECTES) of the state of Minas Gerais, the Floresta-Escola Project, the Fundação de Amparo a Pesquisa de Minas Gerais (FAPEMIG), the Conselho Nacional de Desenvolvimento Científico e Tecnológico ( $\mathrm{CNPq}$ ) and Suzano Papel e Celulose SA for support. JAAMN is supported by a CNPq fellowship. Furthermore, we are grateful for valuable comments from two anonymous reviewers that improved the quality of the text significantly.

\section{References}

APG - Angiosperm Phylogeny Group IV. 2016. An update of the Angiosperm Phylogeny Group classification for the orders and families of flowering plants: APG IV. Botanical Journal of the Linnean Society 181: 1-20

Araujo DSD, Pereira OJ, Peixoto AL. 2008. Campos nativos at the Linhares forest reserve, Espírito Santo, Brazil. In: Thomas WW. (ed.) The Atlantic coastal forest of Northeastern Brazil. New York, The New York Botanical Garden Press. p. 371-385

Baraloto C, Hardy OJ, Paine CET, et al. 2012. Using functional traits and phylogenetic trees to examine the assembly of tropical tree communities. Journal of Ecology 100: 690-701

Batalha MA, Mantovani W, Mesquita Jr HN. 2001. Vegetation stucture in cerrado physiognomies in southeastern Brazil. Brazilian Journal of Biology 61: 475-483

Bell CD, Soltis DE, Soltis PS. 2010. The age and diversification of the angiosperms re-revisited. American Journal of Botany 97: 1296-1303.

Bello F, Lavorel S, Lavergne X, et al. 2012. Hierarchical effects of environmental filters on the functional structure of plant communities: a case study in the French Alps. Ecography 35: 001-010.

Bellwood DR, Wainwright PC, Fulton CJ, Hoey A. 2002. Assembly rules and functional groups at global biogeographical scales. Functional Ecology 16: 557-562

Blomberg SP, Garland T, Ives AR. 2003. Testing for phylogenetic signal in comparative data: behavioral traits are more labile. Evolution 57: 717-745

Cadotte, M.W. Carscadden K, Mirotchnick N. 2011. Beyond species: functional diversity and the maintenance of ecological processes and services. Journal of Applied Ecology 48: 1079-1087

Cahill JR JF, Kembel S, Lamb EG, Keddy PA. 2008. Does phylogenetic relatedness influence the strength of competition among vascular plants? Perspectives in Plant Ecology, Evolution and Systematics 10: 41-50.

Carvalho GH, Batalha MA. 2013. The drivers of tree species richness and density in a Neotropical savannah. Biology Letters 9: 20130412.

Castillo JP, Verdú M, Valiente-Banuet A. 2010. Neighborhood phylodiversity affects plant performance. Ecology 91: 3656-3663.

Cavender-Bares J, Kozak KH, Fine PVA, Kembel SW. 2009. The merging of community ecology and phylogenetic biology. Ecology Letters 12: 693-715

Davies TJ, Barralough TG, Chase MW, Soltis PS, Soltis DE, Savolainen V. 2004. Darwin's abominable mystery: Insights from a supertree of the angiosperms. Proceedings of National Academy of Sciences 101: 1904-1909. 


\section{Markus Gastauer, Amílcar W. Saporetti-Junior, Fernando Valladares and João A. A. Meira-Neto}

Díaz S, Hodgson JG, Thompson K, et al. 2004. The plant traits that drive ecosystems: Evidence from three continents. Journal of Vegetation Science 15: 295-304.

Elton CS. 1927. Animal ecology. London, Sidgwick and Jackson.

Faith DP. 1992. Conservation evaluation and phylogenetic diversity. Biological Conservation 61: 1-10.

Faith DP. 2015 Phylogenetic diversity, functional trait diversity and extinction: avoiding tipping points and worst-case losses. Phil. Trans. R. Soc. B 370: 20140011. http: //dx.doi.org/10.1098/rstb.2014.0011.

Flynn DFB, Mirotchnick N, Jain M, Palmer MI, Naeem S. 2011. Functional and phylogenetic diversity as predictors of biodiversity-ecosystemfunction relationships. Ecology 92: 1573-1581.

Gastauer M, Meira-Neto JAA. 2014. Interactions, environmental sorting and chance : phylostructure of a tropical forest assembly. Folia Geobotanica 49: 443-459.

Gastauer M, Meira-Neto, JAA. 2017. Updated angiosperm family tree for analyzing phylogenetic diversity and community structure. Acta Botanica Brasilica 31: 191-198.

Godoy O, Kraft NJB, Levine JM. 2014. Phylogenetic relatedness and the determinants of competitive outcomes. Ecology Letters 17: 836-844.

Gotelli NJ. 2000. Null model analysis of species co-occurrence patterns. Ecology 81: 2606-2621.

Gotelli NJ, Entsminger GL. 2003. Swap algorithms in null model analysis. Ecology 84: 532-535.

Gotelli NJ, Graves GR. 1996. Null Models in Ecology. Washington, Smithsonian Institution Press.

Hadfield JD, Nakagawa S. 2010. General quantitative genetic methods for comparative biology: phylogenies, taxonomies and multitrait models for continuous and categorical characters. Journal of Evolutionary Biology 23: 494-508.

Hardy OJ. 2008. Testing the spatial phylogenetic structure of local communities: statistical performances of different null models and test statistics on a locally neutral community. Journal of Ecology 96: 914-926.

Harmon LJ, Weir J, Brock CD, Glor RE, Challenger W. 2008. GEIGER: Investigating evolutionary radiations. Bioinformatics 24: 129-131.

Helmus MR. 2007. Separating the determinants of phylogenetic community structure. Ecology Letters 10: 917-925.

Hubbell S. 2001. The unified neutral theory of biodiversity and biogeography. Princeton, Princeton University Press.

Hutchinson GE. 1957. Concluding remarks. Cold Spring Harbor Symposia on Quantitative Biology 22: 415-427.

IBGE - Instituto Brasileiro de Geografia e Estatística. 2004. Mapa de biomas do Brasil. Escala 1: 5.000.000. Rio de Janeiro, IBGE. http: // mapas.ibge.gov.br/biomas2/viewer.htm.

Kelly CK, Bowler MG, Pybus O, Harvey PH. 2008. Phylogeny, niches, and relative abundance in natural communities. Ecology 89: 962-970.

Kembel SW, Cowan PD, Helmus MR, et al.. 2010. Picante: R tools for integrating phylogenies and ecology. Bioinformatics 26: 1463-1464.

Kembel SW, Hubbell SP. 2006. The phylogenetic structure of a neotropical tree community. Ecology 87: S86-S99.

Köppen W. 1923. Die Klimate der Erde. Berlin, Walter de Gruyter.

Kraft NJB, Adler PB, Godoy O, James EC, Fuller S, Levine JM. 2015. Community assembly, coexistence and the environmental filtering metaphor. Functional Ecology 29: 592-599.

Kuhlmann M, Ribeiro JF. 2016. Fruits and frugivores of the Brazilian Cerrado: ecological and phylogenetic considerations. Acta Botanica Brasilica 30: 495-507.

Leibold MA, Economo EP, Peres-Neto P. 2010. Metacommunity phylogenetics: separating the roles of environmental filters and historical biogeography. Ecology Letters 13: 1290-1299.

Losos JB. 2008. Phylogenetic niche conservatism, phylogenetic signal and the relationship between phylogenetic relatedness and ecological similarity among species. Ecology Letters 11: 995-1003.

MacArthur R, Levins R. 1967. The limiting similarity, convergence, and divergence of coexisting species. American Naturalist 101: 377-385.

Mayfield MM, Levine JM. 2010. Opposing effects of competitive exclusion on the phylogenetic structure of communities. Ecology Letters 13: 1085-1093.

McGill BJ, Enquist BJ, Weiher E, Westoby M. 2006. Rebuilding community ecology from functional traits. Trends in Ecology and Evolution 21: 178-185.

Meira-Neto JAA, Souza AL, Lana JM, Valente GE. 2005. Composição florística, espectro biológico e fitofisionomia da vegetação de Muçununga nos municípios de Caravelas e Mucuri, Bahia. Árvore 29: 139-150.

Miazaki AS, Gastauer M, Meira-Neto JAA. 2015. Environmental severity promotes phylogenetic clustering in campo rupestre vegetation. Acta Botanica Brasilica 29: 563-568.

Moro MF, Silva IA, Araújo FS, Lughadbha EN, Meagher TR, Martins FR. 2015. The role of edaphic environment and climate in structuring phylogenetic pattern in seasonally dry tropical plant communities. PLoS ONE 10(3): e0119166. DOI: 10.1371/journal.pone.0119166.

Qian H, Zhang J. 2014. Using an updated time-calibrated family-level phylogeny of seed plants to test for non-random patterns of life forms across the phylogeny. Journal of Sytematics Evolution 52: 423-430.

R Core Team. 2016. R: A language and environment for statistical computing. Vienna, R Foundation for Statistical Computing. http: //www.R-project.org/.

Raunkiaer C. 1934. The life forms of plants and statistical plant geography. Oxford. Oxford University Press.

Ricklefs RE. 2007. History and diversity: explorations at the intersection of ecology and evolution. American Naturalist 170: S56-S70.

Saporetti-Junior AW, Schaefer CEGR, Souza AL, Soares MP, Araujo DSD, Meira-Neto JAA. 2012. Influence of soil physical properties on plants of the Mussununga ecosystem, Brazil. Folia Geobotanica 47: 29-39.

Sargent RD, Ackerly DD. 2008. Plant-pollinator interactions and the assembly of plant communities. Trends in Ecology \& Evolution 23: 123-130.

Simonelli M, Souza AL, Peixoto AL, Silva AL. 2008. Floristic composition and structure of the tree component of a muçununga forest in the Linhares Forest Reserve, Espirito Santo, Brazil. Memoirs of the New York Botanical Garden 100: 251-370.

Soliveres S, Torices R, Maestre FT. 2012. Evolutionary relationships can be more important than abiotic conditions in predicting the outcome of plant-plant interactions. Oikos 121: 1638-1648.

Swenson NG, Enquist BJ. 2009. Opposing assembly mechanisms in a Neotropical dry forest: implications for phylogenetic and functional community ecology. Ecology 90: 2161-2170.

Valiente-Banuet A, Verdú M. 2007. Facilitation can increase the phylogenetic diversity of plant communities. Ecology Letters 10: 1029-1036.

Valiente-Banuet A, Verdú M. 2013. Plant Facilitation and Phylogenetics. Annual Review of Ecology, Evolution, and Systematics 44: 347-366.

Webb CO. 2000. Exploring the phylogenetic structure of ecological communities: an example for rain forest trees. The American Naturalist 156: 145-155.

Webb CO, Ackerly DD, McPeek MA, Donoghue MJ. 2002. Phylogenies and community ecology. Annual Review of Ecology, Evolution, and Systematics 33: 475-505.

Webb CO, Donoghue MJ. 2005. Phylomatic: tree assembly for applied phylogenetics. Molecular Ecology Notes 5: 181-183.

Weiher E, Keddy PA. 1995. Assembly rules, null models, and trait dispersion - new questions from old patterns. Oikos 74: 159-164. 